\title{
Mirjana Petković
}

\section{BEG IZ ANONIMNEGA PISANIA - DELAVNICE DR. NOAHA CHARNEYIA NA FILOZOFSKI FAKULTETI V LJUBLJANI}

\section{VELIKO LJUDI PIŠE, A NE OBJAVI SVOJIH DEL}

Marsikdo od ljudi, ki jih poznam, piše: dnevnik, pesmi, esej, pisma ali celo knjigo. Nekateri pišejo in objavljajo na družbenih omrežjih, predvsem na Facebooku, kjer svoje življenje razgalijo množici »prijateljev«, od katerih je večina le bežnih znancev. Dostikrat svoje mnenje povedo na forumih (a skoraj vedno pod psevdonimom). Vprašanje pa je, kako svoja dela pripraviti tako, da bi jih lahko objavili pri založbi. Ko posameznik napiše neko besedilo, ima pogosto težavo z objavo svojega dela. Napiše pesem, roman ali strokovno razpravo in ta obtiči v računalniku ... Kam s tem gradivom? Včasih nam uspe najti domačega založnika ali prispevek objaviti v slovenski strokovni reviji. Če se posameznik odloči izdati knjigo v samozaložbi, mora prevzeti še vse druge obveznosti v zvezi s financiranjem, promocijo in prodajo. Slovenski bralski trg je razmeroma majhen in število bralcev je omejeno, zato se sprašujemo tudi o tem, kako svoje delo objaviti tam, kjer bo doseglo več bralcev.

\section{KAKO OBJAVITI SVOJE DELO?}

Številni posamezniki ugotavljajo, da ne poznajo nikogar, ki bi njihovo delo spravil tja, kjer je veliko potencialnih bralcev. Ugotavljajo tudi, da obstajajo jezikovne ovire, saj slovenščina ni med najbolj razširjenimi jeziki, zato se sprašujejo, kdo bo bral njihovo knjigo, če je ne razume. Poleg tega so finančne zadeve nekakšna tabu tema in se je ljudem nerodno pogovarjati o »tarifah«. Neizkušenost na tem področju pogosto povzroči tako veliko zadrego, da se avtorji rajši odpovedo objavi. Za nekatere objave, na primer pri knjigi, založnik od avtorja pričakuje ali celo zahteva, da promovira svoje delo, da intervju in podobno. To za nekatere pomeni velik izziv, saj morda avtor ni ravno vešč nastopanja, nima izkušenj z govori ali vedenjem pred kamero.

Pisatelj raje ostane anonimen. Njegovo delo ne zaživi. Nihče ga ne sliši, nihče ga ne bere. Velika škoda, kajti ljudje potrebujemo drug drugega kot priče svojega življenja. Ne le kot 
priče naše zunanjosti, ampak kot priče naše notranjosti. V bistvu želimo, da drugi vedo, kaj občutimo, o čem razmišljamo. Ta pojav je še posebej izrazit pri starejših, ki želijo svoje dolgoletne izkušnje prenesti na mlajše rodove. Tako pri mladih kot pri starejših posameznikih se iz notranjosti sliši glas: »Imam nekaj povedati in želim, da me slišijo (berejo).«In potem se pojavijo tehnične ovire, kot je iskanje agenta, prevajalca in založnika.

Na Filozofski fakulteti Univerze v Ljubljani pripravljamo izobraževalne delavnice, ki omogočajo posameznikom, da se naučijo pripraviti svoja dela za objavo in jih nato promovirati v javnosti. ${ }^{1}$

\section{TRI DELAVNICE}

Predavatelj dr. Noah Charney ${ }^{2}$ udeležencem na svojih delavnicah ponudi konkretne odgovore in predloge za rešitev omenjenih težav.

Na delavnici Writing for Publication udeležencem svetuje, kako stopiti iz anonimnosti ter poiskati agenta in založnika v angleško govorečih državah. Njegovi nasveti niso namenjeni zgolj bodočim profesionalnim pisateljem ali pesnikom, temveč nagovarjajo vse tiste, ki želijo pisati in objavljati. Posebno pozornost namenja načinu, kako pritegniti pozornost bralcev, da bodo z branjem vztrajali do konca besedila. Na delavnici lahko vsak prepozna svojo pot, ne glede na žanr, v katerem piše. Koristne nasvete dobi novinar, pesnik, pisatelj romana, pisatelj otroških knjig (po različnih kategorijah starosti otrok), pisec znanstvenih in strokovnih besedil. Razprava poteka o konkretnih dilemah, s katerimi se srečujejo pisci, kot so: v katerih primerih je bolje pisati v prvi osebi ednine in kdaj v tretji osebi, kdaj pišem v sedanjem času in kdaj v pretekliku ter koliko oseb je dobro imeti pri intervjuju.

Predavatelj postreže s primeri, ki govorijo o tem, kdaj je založniku smotrno ponuditi le del besedila (vzorec poglavja) in nadaljevati pisanje potem, ko je naročilo sprejeto, in kdaj je dobro imeti »na zalogi« celotno besedilo.

Udeleženci se na delavnici spoznajo z mednarodnim delovanjem mreže založnikov in njihovih agentov ter načinom odločanja o objavi nekega teksta. Kaj je tisto, kar bo založnika pritegnilo, da se bo potem, ko bo prebral naše pismo, ukvarjal z našim tekstom, in kaj je tisto, kar bi ga odvrnilo od nadaljnjega branja? Založniki so namreč dobesedno zasuti s predlogi, ki vsakodnevno prihajajo po elektronski pošti z različnih koncev sveta. Zato ima delavnica poseben poudarek na pripravi »prvih vtisov«, ki se ustvarijo že v prvi alineji, prvem odstavku, na prvi strani in prvem poglavju besedila. Ti so največkrat odločilni za založnika ali njegovega agenta. Dr. Charney na delavnici predstavi vzorce pisem, s

1 http://www.ff.uni-lj.si/1/Dejavnosti-FF/Jezikovni-tecaji-in-drugi-seminarji/Drugi-tecaji-in-seminarji-.aspx

2 Dr. Noah Charney (1979) je uveljavljen pisatelj in umetnostni zgodovinar, profesor na Yale University v New Havnu in na Ameriški univerzi v Rimu. Doktoriral je iz umetnostne zgodovine na Filozofski fakulteti Univerze v Ljubljani na temo Plečnikove arhitekture, njegova ožja specialnost pa je odkrivanje tatvin in ponaredkov umetniških del. V ta namen je bil pobudnik in soustanovitelj neprofitnega inštituta ARCA, v okviru katerega za odkrivanje tatvin umetniških del sodelujejo tako FBI kot ScotlandYard in Carabinieri. http:// en.wikipedia.org/wiki/Noah_Charney 
katerimi nagovorimo bodočega agenta, založnika in prevajalca. Udeleženci analizirajo strukturo in vsebino pisma ter dobijo nasvete v zvezi s predstavitvijo sebe in dela, ki ga ponujajo založniku. Ravno tako dobijo vrsto nasvetov v zvezi z običajnimi cenami in provizijami, ki so del dogovora z agenti in založniki. Predavatelj spodbuja udeležence, da se osvobodijo nelagodja, ko govorijo o finančni plati objave svojega dela. Predavatelj se na delavnici posveča tudi iskanju založnikov po spletnih straneh, priporoča ključne besede, dobre založniške hiše, znanstvene revije in druge založnike glede na zanimanje udeležencev. Udeleženci se seznanijo tudi s primeri, ko je besedilo dobro izdati v samozaložbi, ter ob tem spoznajo tudi pasti samozaložništva.

Na delavnici si ogledajo primere dobre prakse objav besedil različnih zvrsti, ki jih prinese predavatelj s seboj, nato pa povabi udeležence, da prispevajo svoje tekste, ki jih skupaj s predavateljem analizirajo, ugotavljajo dobre strani besedila in morebitne pomanjkljivosti, ki bi jih bilo treba odpraviti. $\mathrm{V}$ analizi vedno prevladuje prizanesljiva argumentacija, nasveti so podani v dobrohotnem vzdušju. Tako se udeleženci večinoma počutijo sproščeno in delavnico zapustijo $\mathrm{v}$ dobrem razpoloženju, motivirani in razbremenjeni negotovosti ter oboroženi z nasveti, kako izraziti sebe skozi pisano besedo, ki bo dosegla čim večji krog bralcev.

Delavnica Writing for Anglophone Readers je namenjena posebnostim, ki so značilne za bralce iz angleško govorečega okolja (Velika Britanija, ZDA in Kanada). Bralna publika iz teh držav je številčna in založništvo $v$ teh državah je zelo razvito, zato je tema izredno zanimiva.

Način podajanja »snovi« za te bralce se namreč razlikuje od pisanja za bralce iz Srednje Evrope. Dr. Charney približa razliko med bralci iz različnih okoljih na primeru univerzitetnih predavanj, saj gre za različne navade, ki ustvarjajo različne skupine bralcev. V šali večkrat pove, da francoski pisatelj Victor Hugo danes v ZDA ne bi zaslužil niti centa in bi verjetno umrl od lakote, saj njegovih opisov pokrajine na 30 uvodnih straneh nihče ne bi bral.

$\mathrm{Na}$ delavnici se obravnavajo različna besedila. Na začetku se udeleženci ukvarjajo z besedili, ki so uvod v delo. Ta del besedila je za bralce iz angleško govorečega okolja izredno pomemben. V nadaljevanju analizirajo pripravljene tekste različnih žanrov. Skozi tekste in razpravo spoznavajo razlike pri podajanju snovi v francosko-nemškem okolju in v angleškem. Obravnavane razlike se nanašajo predvsem na način argumentiranja. Potreba po argumentaciji, ki se opira na znana dejstva, pri bralcih iz angleško govorečih držav obstaja ne glede na zvrst literature, ki jo berejo, poudarja dr. Charney. Poleg znanstvenih del in novinarskih prispevkov je ta potreba izražena tudi pri esejih, romanih in drugih besedilih, saj dejstva in dokazi vplivajo na verodostojnost dela. Predavatelj udeležence pouči še o zanimivih vprašanjih, kot so: kakšne so značilnosti uspešnic, na katerih spletnih straneh najdemo založnike za posamezne zvrsti objav, kako si zagotoviti promocijo prek spleta.

Tretja delavnica Public Speaking pa je priprava na javno nastopanje v različnih situacijah, kot so predstavitve, govori, intervjuji. Predavatelj svetuje, kako pripraviti strategijo predstavitve, ki bo zanimiva in učinkovita, pokaže, kako izpeljati prepričljiv in dinamičen 
govor. Udeleženci spoznajo, kakšni so načini prepričevanja z dejstvi (argumentirano prepričevanje). Dr. Charney obravnava tako komunikacijo z manjšim številom udeležencev (na primer intervju) kot predstavitev večjemu avditoriju, kar vse pospremi s svojimi izkušnjami pri delu na televiziji.

Vse tri omenjene delavnice obiskujejo udeleženci različnih poklicev in starosti ter statusov (študenti, zdravniki, odvetniki, učitelji, novinarji, pisatelji, podjetniki), kar prispeva k zanimivosti dogajanja. Usposabljanje udeležencem omogoča stopiti stopnico više v osebnostni rasti, jim vliva pogum in pripomore $\mathrm{k}$ sproščenemu komuniciranju z okoljem. 